\title{
Status of the MODIS Level 1B Algorithms and Calibration Tables
}

\author{
X. Xiong and V.V. Salomonson \\ Sciences Exploration Directorate \\ NASA/GSFC, Greenbelt, MD 20771 \\ J. Kuyper and L. Tan \\ Science Applications International Corp. \\ 7501 Forbes Blvd., Lanham, MD 20706 \\ K. Chiang and J. Sun \\ Science Systems and Applications, Inc. \\ 10210 Greenbelt Road, Lanham, MD 20706 \\ W.L. Barnes \\ JCET, University of Maryland, Baltimore County \\ 1000 Hilltop Circle, Baltimore, MD 212250
}

\begin{abstract}
The Moderate Resolution Imaging Spectroradiometer (MODIS) makes observations using 36 spectral bands with wavelengths from 0.41 to $14.4 \mu \mathrm{m}$ and nadir spatial resolutions of $0.25 \mathrm{~km}, 0.5 \mathrm{~km}$, and $1 \mathrm{~km}$. It is currently operating onboard the NASA Earth Observing System (EOS) Terra and Aqua satellites, launched in December 1999 and May 2002, respectively. The MODIS Level 1B (L1B) program converts the sensor's on-orbit responses in digital numbers to radiometrically calibrated and geo-located data products for the duration of each mission. Its primary data products are top of the atmosphere (TOA) reflectance factors for the sensor's reflective solar bands (RSB) and TOA spectral radiances for the thermal emissive bands (TEB). The L1B algorithms perform the TEB calibration on a scan-by-scan basis using the sensor's response to the on-board blackbody (BB) and other parameters which are stored in Lookup Tables (LUTs). The RSB calibration coefficients are processed offline and regularly updated through LUTs. In this paper we provide a brief description of the MODIS L1B calibration algorithms and associated LUTs with emphasis on their recent improvements and updates developed for the MODIS collection 5 processing. We will also discuss sensor on-orbit calibration and performance issues that are critical to maintaining L1B data product quality, such as changes in the sensor's response versus scan-angle.
\end{abstract}

\section{INTRODUCTION}

Two Moderate Resolution Imaging Spectroradiometer (MODIS) instruments, a Proto-flight Model (PFM) and a Flight Model 1 (FM1), were designed and built by Raytheon / Santa Barbara Remote Sensing (SBRS), Goleta, California, for the NASA's Earth Observing System (EOS) missions that promote the continuity of essential science and environmental data records [1-5]. The MODIS PFM onboard the Terra spacecraft has been in operation for more than 5 years since its launch in December 1999 and the FM1 for nearly 3 years onboard the Aqua spacecraft launched in May 2002. Each instrument makes continuous observations over a wide field-of-view (FOV) in 36 spectral bands with wavelengths from 0.41 to $14.4 \mu \mathrm{m}$ and at nadir spatial resolutions of $0.25 \mathrm{~km}, 0.5 \mathrm{~km}$, and $1 \mathrm{~km}$. Table 1 lists key sensor specified parameters and characteristics.

Table 1 MODIS Specified Parameters and Characteristics

\begin{tabular}{|c|c|}
\hline Orbit & $\begin{array}{l}\text { 705km (altitude) } \\
\text { Sun-synchronous, near-polar, circular } \\
\text { 10:30AM descending node (Terra) } \\
\text { 1:30PM ascending node (Aqua) }\end{array}$ \\
\hline Spectral Range & $\begin{array}{l}20 \text { reflective solar bands ( } 1-19 \text { and } 26) \text { from } \\
0.41 \text { to } 2.2 \mu \text {, } \\
16 \text { thermal emissive bands (20-25 and } 27-36) \\
\text { from } 3.7 \text { to } 14.4 \mu\end{array}$ \\
\hline $\begin{array}{r}\text { Spatial Resolution } \\
\text { (nadir) }\end{array}$ & $\begin{array}{l}0.25 \mathrm{~km} \text { (bands } 1-2,40 \text { detectors along-track and } \\
4 \mathrm{sub} \text {-samples each cross-track) } \\
0.5 \mathrm{~km} \text { (bands } 3-7,20 \text { detectors along-track and } \\
2 \text { sub-samples each cross-track) } \\
1 \mathrm{~km} \text { (bands } 8-36,10 \text { detectors along-track) }\end{array}$ \\
\hline Swath & $\begin{array}{l}10 \text { (1 km resolution) pixels along-track by } 1354 \\
(1 \mathrm{~km} \text { resolution) pixels cross-track }\end{array}$ \\
\hline Scan Rate & $20.3 \mathrm{rpm}(1.477 \mathrm{~s} / \mathrm{scan})$ \\
\hline Scan Range & $\begin{array}{l} \pm 55^{\circ} \text { from nadir or angle of incident (AOI) to } \\
\text { the scam mirror from } 10.5^{\circ} \text { to } 65.5^{\circ}\end{array}$ \\
\hline Digitization & 12 bits ADC \\
\hline Data Rate & $\begin{array}{l}\text { 11Mbps daytime } \\
\text { 3.3Mbps nighttime }\end{array}$ \\
\hline $\begin{array}{r}\text { On-board } \\
\text { Calibrators (OBCs) }\end{array}$ & $\begin{array}{l}\text { Solar diffuser (SD) } \\
\text { Solar diffuser stability monitor (SDSM) } \\
\text { Blackbody (BB) } \\
\text { Spectro-radiometric calibration assembly } \\
\text { (SRCA) }\end{array}$ \\
\hline $\begin{array}{r}\text { Focal Plane } \\
\text { Assemblies (FPAs) }\end{array}$ & $\begin{array}{l}\text { Visible (VIS) } \\
\text { Near infrared (NIR) } \\
\text { Short- and mid-wave infrared (SMIR) } \\
\text { Long-wave infrared (LWIR) }\end{array}$ \\
\hline $\begin{array}{r}\text { Spectral Bands and } \\
\text { Detectors }\end{array}$ & $\begin{array}{l}36 \text { bands } \\
490 \text { detectors (including time-delay and } \\
\text { integration detectors used for the high/low gain } \\
\text { bands } 13 \text { and } 14 \text { ) }\end{array}$ \\
\hline
\end{tabular}

The MODIS Level 1B (L1B) algorithms convert the sensor's responses in digital numbers (DN) to top of the 


\section{Report Documentation Page}

Form Approved

OMB No. 0704-0188

Public reporting burden for the collection of information is estimated to average 1 hour per response, including the time for reviewing instructions, searching existing data sources, gathering and maintaining the data needed, and completing and reviewing the collection of information. Send comments regarding this burden estimate or any other aspect of this collection of information,

including suggestions for reducing this burden, to Washington Headquarters Services, Directorate for Information Operations and Reports, 1215 Jefferson Davis Highway, Suite 1204, Arlington

VA 22202-4302. Respondents should be aware that notwithstanding any other provision of law, no person shall be subject to a penalty for failing to comply with a collection of information if it

does not display a currently valid OMB control number.

\begin{tabular}{|c|c|c|}
\hline $\begin{array}{l}\text { 1. REPORT DATE } \\
\mathbf{2 5} \text { JUL } 2005\end{array}$ & $\begin{array}{l}\text { 2. REPORT TYPE } \\
\text { N/A }\end{array}$ & $\begin{array}{l}\text { 3. DATES COVERED } \\
\text { - }\end{array}$ \\
\hline \multirow{3}{*}{\multicolumn{2}{|c|}{ Status of the MODIS Level $1 B$ Algorithms and Calibration Tables }} & 5a. CONTRACT NUMBER \\
\hline & & 5b. GRANT NUMBER \\
\hline & & 5c. PROGRAM ELEMENT NUMBER \\
\hline \multirow{3}{*}{\multicolumn{2}{|c|}{ 6. AUTHOR(S) }} & 5d. PROJECT NUMBER \\
\hline & & 5e. TASK NUMBER \\
\hline & & 5f. WORK UNIT NUMBER \\
\hline \multicolumn{2}{|c|}{$\begin{array}{l}\text { 7. PERFORMING ORGANIZATION NAME(S) AND ADDRESS(ES) } \\
\text { Sciences Exploration Directorate NASA/GSFC, Greenbelt, MD } 20771\end{array}$} & $\begin{array}{l}\text { 8. PERFORMING ORGANIZATION } \\
\text { REPORT NUMBER }\end{array}$ \\
\hline \multirow{2}{*}{\multicolumn{2}{|c|}{ 9. SPONSORING/MONITORING AGENCY NAME(S) AND ADDRESS(ES) }} & 10. SPONSOR/MONITOR'S ACRONYM(S) \\
\hline & & $\begin{array}{l}\text { 11. SPONSOR/MONITOR'S REPORT } \\
\text { NUMBER(S) }\end{array}$ \\
\hline
\end{tabular}

12. DISTRIBUTION/AVAILABILITY STATEMENT

Approved for public release, distribution unlimited

13. SUPPLEMENTARY NOTES

See also ADM001850, 2005 IEEE International Geoscience and Remote Sensing Symposium Proceedings (25th) (IGARSS 2005) Held in Seoul, Korea on 25-29 July 2005.

14. ABSTRACT

15. SUBJECT TERMS

16. SECURITY CLASSIFICATION OF:

a. REPORT

unclassified b. ABSTRACT

unclassified c. THIS PAGE

unclassified
17. LIMITATION OF ABSTRACT

$\mathbf{U U}$
18. NUMBER OF PAGES

4 19a. NAME OF RESPONSIBLE PERSON 
atmosphere (TOA) reflectance factors for the reflective solar bands (RSB) and TOA spectral radiances for the thermal emissive bands (TEB). They are designed based on instrument performance determined from comprehensive pre-launch and on-orbit calibration and characterization [6-9]. Two separate versions of the L1B software and corresponding Look-up Tables (LUTs), one for Terra MODIS and the other for Aqua MODIS, are maintained to accommodate differences between the two sensors and to track their on-orbit changes independently. The NASA MODIS Characterization Support Team (MCST) is responsible for the tasks of performing sensor calibration and characterization, maintaining and improving the L1B algorithms, and deriving and updating the calibration parameters in the L1B LUTs. In this paper we provide a short description of the MODIS L1B calibration algorithms and associated LUTs and highlight the latest improvements and updates implemented for the MODIS collection 5 processing.

\section{OVERVIEW OF MODIS L1B CALIBRATION ALGORITHMS}

The MODIS L1B calibration is performed for each band, detector, sub-sample, and mirror side (BDSM). The algorithm consists of two major modules: one for the reflective solar bands (RSB) and the other for the thermal emissive bands (TEB). Details of the MODIS TEB and RSB calibration algorithms are provided in papers given by Xiong, et al [1011]. The L1B input includes the L1A data (raw counts), geolocation data, and L1B LUT files for the TEB, RSB and quality assurance (QA). A simplified L1B data processing flow diagram is shown in Figure 1.

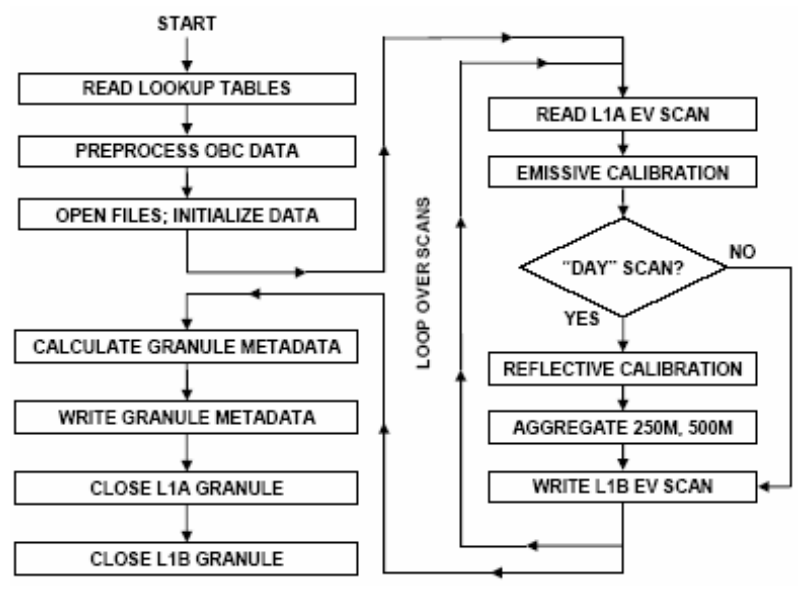

Figure 1 MODIS Level 1B (L1B) Flow Diagram

The thermal emissive bands (20-25 and 27-36) are calibrated by an on-board blackbody on a scan-by-scan basis using a quadratic algorithm that corrects for instrument background (from the sensor's space view), thermal emissions from the scan mirror and scan cavity, and response versus scan angle (RVS). An optical leak correction is applied to bands 3236 (Terra only). The retrieved Earth view (EV) radiance is converted to a scaled integer (SI).
The reflective solar bands (1-19 and 26) are calibrated using a solar diffuser (SD) and solar diffuser stability monitor (SDSM) system. The SD/SDSM calibration is typically performed bi-weekly (weekly for the first year) and analyzed off line by the MCST. The RSB calibration uses a linear algorithm with calibration coefficients updated through the LUTs. The algorithm corrects for instrument background, temperature, and response versus scan angle (RVS). A thermal leak correction is applied to the SWIR bands (5-7 and 26). The retrieved EV reflectance factor is converted to a scaled integer (SI). The RSB calibration is executed after the TEB calibration.

The L1B output consists of calibrated radiances and reflectance factors and is organized in three Hierarchical Data Format (HDF) files corresponding to MODIS' three spatial resolutions and their associated metadata files. The following expressions are used to convert the SI to the scene TOA radiances or reflectance factors.

For TEB radiances:

$$
\text { Radiance }=\text { radiance_scales } *(S I-\text { radiance_offsets })
$$

For RSB reflectance factors:

Reflectance $=$ reflectance _scales $*(S I-$ reflectance_offsets $)$

For RSB radiances:

$$
\text { Radiance }=\text { Reflectance } \cdot \frac{\text { Solar_Irradiance_over_pi }}{(\text { Earth }- \text { Sun_Distance })^{2}}
$$

The band dependent coefficients of radiance_scales, radiance_offsets, reflectance_scales, and reflectance_offsets are stored as scientific data set (SDS) attributes within the Level 1B output files. The "Earth-Sun_Distance" and "Solar_Irradiance_over_pi" are provided as global attributes. The L1B also produces a separate file containing on-board calibration $(\mathrm{OBC})$ data and key instrument telemetry. The OBC file is primarily used for off-line calibration and characterization purposes.

\section{MODIS L1B LOOK-UP TABLES}

The MODIS Level 1B (L1B) code Look-up Tables (LUTs) are organized into three groups: one for the TEB calibration, another for the RSB calibration, and a third one for quality assurance (QA). Each individual LUT is implemented in the appropriate HDF file as either a global attribute or a Scientific Data Set (SDS) [12]. Currently there are 98 LUTs (40 TEB, 34 RSB, and 24 QA) for the Terra MODIS L1B code and 101 LUTs (43 TEB, $34 \mathrm{RSB}$, and $24 \mathrm{QA}$ ) for the Aqua MODIS L1B code. Aqua MODIS has 3 extra TEB LUTs compared with Terra MODIS. These extra LUTs are used to provide predetermined linear gain coefficients for bands 33, 35, and 36 at high $\mathrm{BB}$ temperatures during $\mathrm{BB}$ warn-up process when their responses saturate (a feature that only appears in the Aqua MODIS). 
Some of the LUTs included in the HDF files are not used for calibration, such as those used for serial numbers, metadata items, and code version numbers. Some of the LUTs are constant and some may depend on the data collection time in either a "step function" or "piecewise linear" style. Among calibration LUTs, some were derived from pre-launch calibration and characterization, such as the relative spectral response (RSR), the temperature correction coefficients, and corresponding reference temperatures. Some calibration LUTs are derived from on-orbit measurements and updated as needed. Examples include the RSB response versus scan angle (RVS) and SD calibration coefficients for the reflectance factor retrieval. The MCST at NASA/GSFC is responsible for determining the contents of all L1B LUTs and for maintaining and updating (adding, deleting, or changing) them.

\section{STATUS OF MODIS L1B AND LUTS}

Terra MODIS has been in operation for more than five years since its launch in December 1999. Thus far there have been four major configurations used for the instrument operation. As shown in Table 2 that there are 12 versions of the L1B code used in data production. Each change was made to improve the L1B algorithms or to mitigate code deficiencies. Many versions of the LUTs have been updated either to the track sensor's response changes over time or to accommodate changes in operational configuration.

Table 2 Terra MODIS L1B code and LUT versions

\begin{tabular}{|c|l|l|}
\hline Code Version & Production Time & LUTs Version \\
\hline V2.3.2 & $03 / 17 / 2000(0772000) 00: 00$ & 3 \\
\hline V2.4.2 & $06 / 19 / 2000(1712000) 00: 00$ & 0 \\
\hline V2.4.3 & $08 / 18 / 2000(2312000) 14: 00$ & 1 \\
\hline V2.4.4 & $10 / 13 / 2000(2872000) 19: 55$ & $0-2$ \\
\hline V2.5.4 & $11 / 23 / 2000(3282000) 15: 55$ & 0 \\
\hline V2.5.5 & $02 / 13 / 2001(0442001) 13: 55$ & 1,2 \\
\hline V3.0.0 & $05 / 24 / 2001(1442001) 00: 00$ & $2-7$ \\
\hline V3.0.1 & $02 / 25 / 2002(0562002) 00: 00$ & 0,1 \\
\hline V4.1.2 & $01 / 30 / 2003(0302003) 01: 55$ & $1-11$ \\
\hline V4.2.0 & $08 / 22 / 2003(2342003) 02: 00$ & $3-9$ \\
\hline V4.3.0 & $12 / 22 / 2003(3562003) 22: 35$ & $1-9,11-25$ \\
\hline V5.0.6 & $03 / 07 / 2005(0662005) 23: 55$ & 1,2 \\
\hline
\end{tabular}

Since its launch in May 2002, Aqua MODIS has been in operation for nearly three years. Unlike its Terra predecessor, the Aqua MODIS has been operated using the same B-side electronic configuration for the entire mission. Table 3 is a list of its L1B code and LUT versions.

Table 3 Aqua MODIS L1B code and LUT versions

\begin{tabular}{|l|l|l|}
\hline Code Version & Production Time & LUTs Version \\
\hline V3.1.0 & $06 / 07 / 2002(158$ 2002) 18:10 & $0-3$ \\
\hline V4.1.1 & $10 / 31 / 2002(3042002) 00: 15$ & 0,1 \\
\hline V4.1.3 & $01 / 22 / 2003(022$ 2003) 09:55 & $0-11$ \\
\hline V4.2.1 & $08 / 21 / 2003(2332003) 12: 00$ & $4-8$ \\
\hline V4.3.1 & $06 / 02 / 2002(1832002) 15: 25$ & $1-16$ \\
\hline V5.0.7 & Scheduled for May 2005 & 1 \\
\hline
\end{tabular}

The latest MODIS data collection will be produced using version 5 of the L1B code. The Terra collection 5 (V5.0.6) was started in March 2005 and the Aqua collection 5 will start in May 2005. In addition to the NASA Goddard Distributed Active Archive Center (GDAAC), selected L1B products have also been produced at the MODIS Adaptive Processing System (MODAPS) and at the MODIS Ocean Color Data Processing System.

Only a few minor code changes were made in L1B version 5, including improving code portability, enabling B21 calibration with mirror side dependency (for reducing image striping), and adding new LUTs for SWIR correction with flexible detector dependency in order to avoid using noisy detectors in the correction algorithm. Overall improvements are primarily coming from better calibration and LUTs that are developed using long-term consistent calibration data.

In version 5 the Terra TEB will use the response versus scan-angle (RVS) derived from on-orbit spacecraft pitch maneuvers made on March 26 and April 14, 2003 for the entire mission, replacing the relative RVS determined from scanning the closed nadir aperture door. For the reflective solar bands of both Terra and Aqua MODIS, on-orbit RVS changes of mirror side one are updated using each sensor's response trending from SD calibrations and lunar observations. The RSB RVS changes of mirror side two are derived relative to mirror side one using the trending of mirror side response ratios at various angles of incidence (AOI). Several QA LUTs have been updated based on the detectors' on-orbit performance. Complete histories of L1B code versions and LUT updates for both Terra and Aqua MODIS are posted on the MCST web page (http://www.mcst.ssai.biz/mcstweb/L1B/ product.html).

Other documents that describe the algorithms, function and applications of the L1B code and LUTs include "MODIS Level 1B Algorithm Theoretical Basis Document", "MODIS Level 1B Product User's Guide", "MODIS LUT Information Guide", "MODIS Level 1B In-Granule Calibration Code High Level Design", and "MODIS Level 1B Products Data Dictionary". These are also provided at the MCST web page (home page http://www.mcst.ssai.biz/mostweb/).

\section{SUMMARY}

Since their launches in December 1999 and May 2002, Terra and Aqua MODIS together have produced nearly eight years of data products for the science community's studies of the Earth system and its land, oceans, and atmosphere. Working together with the MODIS Science Team members and sensor vendor representatives, the NASA MODIS Characterization Support Team (MCST) is responsible for providing instrument on-orbit calibration and characterization, maintaining and improving the L1B algorithms, and updating the calibration parameters in the L1B LUTs. Currently two separate versions of the L1B software and LUTs have been maintained and updated for the data processing, one for the Terra and the other for the Aqua MODIS. This paper has presented the status of the MODIS L1B algorithms and associated LUTs, including the latest improvements and updates made for the MODIS collection 5 processing. 


\section{ACKNOWLEDGEMENT}

The authors would like to thank members of the MODIS Characterization Support Team for their contributions to the design, development, and improvement of the L1B algorithms, code, and LUT updates (past and present), especially Jim Rogers and Alice Isaacman.

\section{REFERENCES}

[1] W.L. Barnes and V.V. Salomonson, "MODIS: A global image spectroradiometer for the Earth Observing System", Critical Reviews of Optical Science and Technology, CR47, 285-307, 1993.

[2] V.V. Salomonson, W.L. Barnes, X. Xiong, S. Kempler and E. Masuoka, "An Overview of the Earth Observing System MODIS Instrument and Associated Data Systems Performance", Proceedings of IGARSS, 2002.

[3] C.L. Parkinson, "Aqua: An Earth-Observing Satellite Mission to Examine Water and Other Climate Variables," IEEE Transaction on Geoscience and Remote Sensing, 41 (2), 173-183, 2003.

[4] W.L. Barnes, X. Xiong, and V.V. Salomonson, "Status of Terra MODIS and Aqua MODIS," Proceedings of IGARSS, 2002.

[5] W.L. Barnes, V.V. Salomonson, B. Guenther, and X. Xiong, "Development, Characterization, and Performance of the EOS MODIS Sensors", Proceedings of SPIE - Earth Observing Systems VIII, 5151, 337-345, 2003.

[6] W.L. Barnes, T. Pagano, and V.V. Salomonson, "Prelaunch characteristics of the Moderate Resolution Imaging Spectroradiometer
(MODIS) on EOS-AM1," IEEE Transactions on Geoscience and Remote Sensing, 36 (4), 1088-1100, July 1998.

[7] B. Guenther, G. Godden, X. Xiong, E. Knight, S. Qiu, H. Montgomery, M. Hopkins, M. Khayat, and Z. Hao, "Prelaunch algorithm and data format for the level 1 calibration products for the EOS-AM1 Moderate Resolution Imaging Spectroradiometer (MODIS)", IEEE Transaction on Geoscience and Remote Sensing, 36 (4), 1142-1151, 1998.

[8] B. Guenther, X. Xiong, V.V. Salomonson, W.L. Barnes, and J. Young, "On-orbit performance of the Earth Observing System (EOS) Moderate Resolution Imaging Spectroradiometer (MODIS); first year of data," Remote Sensing of Environment, 83, 16-30, 2002.

[9] X. Xiong, K. Chiang, J. Esposito, B. Guenther, and W.L. Barnes, "MODIS On-orbit Calibration and Characterization," Metrologia, 40, 89-92, February 2003.

[10] X. Xiong, J. Sun, J. Esposito, B. Guenther, and W.L. Barnes, "MODIS Reflective Solar Bands Calibration Algorithm and On-orbit Performance," Proceedings of SPIE - Optical Remote Sensing of the Atmosphere and Clouds III, 4891, 2002.

[11] X. Xiong, K. Chiang, B. Guenther, and W.L. Barnes, "MODIS Thermal Emissive Bands Calibration Algorithm and On-orbit Performance," Proceedings of SPIE - Optical Remote Sensing of the Atmosphere and Clouds III, 4891, 2002.

[12] A. Isaacman, G. Toller, B. Guenther, W.L. Barnes, and X. Xiong, 'MODIS Level 1B Calibration and Data Products," Proceedings of SPIE - Earth Observing Systems VIII, 5151, 552-562, 2003. 